
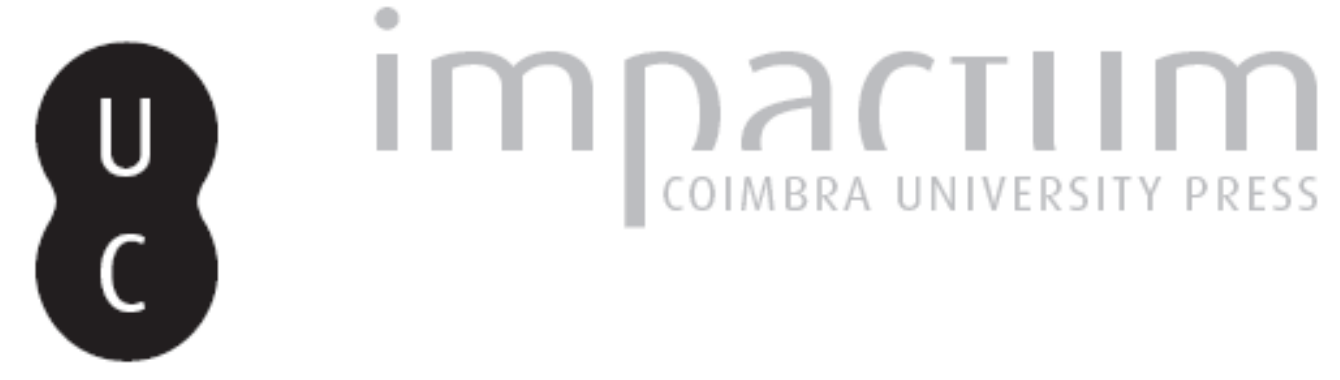

\title{
A avaliação pericial do estado de saúde: uma problemática em Clínica Forense
}
Autor(es):
Oliveira, Carina; Silva, Rosário Lemos; Costa, Graça Santos; Costa, Diogo Pinto da; Corte Real, Francisco; Vieira, Duarte Nuno

Publicado por: Imprensa da Universidade de Coimbra

URL persistente:

URI:http://hdl.handle.net/10316.2/33225

DOI:

DOI:http://dx.doi.org/10.14195/1647-8630_22_8

Accessed : $\quad$ 26-Apr-2023 10:53:05

A navegação consulta e descarregamento dos títulos inseridos nas Bibliotecas Digitais UC Digitalis, UC Pombalina e UC Impactum, pressupõem a aceitação plena e sem reservas dos Termos e Condições de Uso destas Bibliotecas Digitais, disponíveis em https://digitalis.uc.pt/pt-pt/termos.

Conforme exposto nos referidos Termos e Condições de Uso, o descarregamento de títulos de acesso restrito requer uma licença válida de autorização devendo o utilizador aceder ao(s) documento(s) a partir de um endereço de IP da instituição detentora da supramencionada licença.

Ao utilizador é apenas permitido o descarregamento para uso pessoal, pelo que o emprego do(s) título(s) descarregado(s) para outro fim, designadamente comercial, carece de autorização do respetivo autor ou editor da obra.

Na medida em que todas as obras da UC Digitalis se encontram protegidas pelo Código do Direito de Autor e Direitos Conexos e demais legislação aplicável, toda a cópia, parcial ou total, deste documento, nos casos em que é legalmente admitida, deverá conter ou fazer-se acompanhar por este aviso.

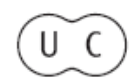




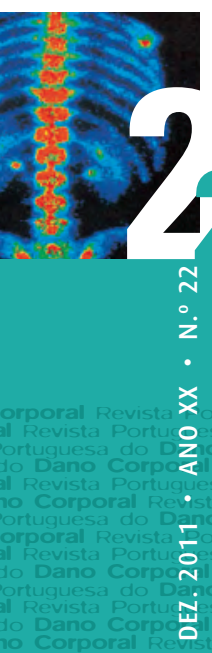

$$
\text { REVISTA PORT U/GUESA }
$$

do
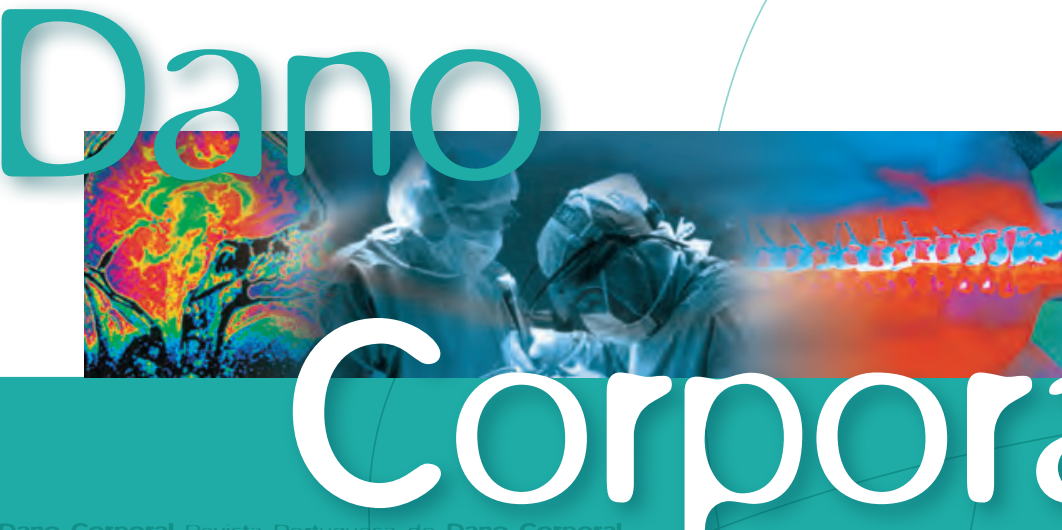

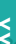

Oesa do Dano Corporal Revista Portuguesa do Dano Corporal

Zo Corporal Revista Portuguesa do Dano Corporal Revista Portuguesa do Dano Corporal

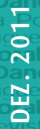

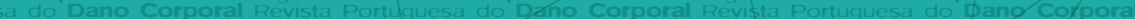

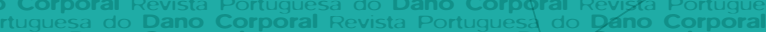

Revista Portuguesa do Dano Corporal Revista Rortuguesa do Dano Corporal
Ro Corporal Revista Portuguesa do Dano Corpgral Revista Portuguesa do Dano Corporal

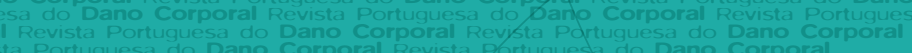




\title{
A avaliação pericial do estado de saúde. Uma problemática em Clínica Forense
}

\author{
Carina Oliveira ${ }^{(1,3)}$, Rosário Lemos Silva ${ }^{(1,3)}$, Graça Santos Costa ${ }^{(1,3)}$, \\ Diogo Pinto da Costa ${ }^{(1,3)}$, Francisco Corte Real ${ }^{(1-3)}$, Duarte Nuno Vieira ${ }^{(1,2,3)}$
}

\section{INTRODUÇÃO}

Concretizada no âmbito da Clínica Forense, a avaliação pericial do estado de saúde continua a constituir, indiscutivelmente, uma das situações problemáticas no domínio da avaliação dos danos corporais, representando, ainda hoje, um desafio na prática pericial médico-legal. Isto atendendo quer à frequente complexidade do objeto da perícia, quer à grande variabilidade de situações que, neste contexto, são solicitadas aos serviços periciais médico-legais.

Como sempre, também aqui é crucial dar resposta ao objeto da perícia, ao que é solicitado pela entidade requisitante, seja esta a competente autoridade judiciária, uma companhia seguradora, a entidade patronal ou o próprio examinado. Como sempre também, a resposta a dar deverá ser imparcial e objetiva, satisfazendo cabalmente os fins a que se destina, sem deixar de respeitar as normas específicas que a regem.

Até 21 de Janeiro de 2008, era absolutamente pacífico que o instrumento de avaliação (tabela) aplicável em tais situações, sempre que era solicitada a atribuição de incapacidade, seria a Tabela aprovada no Decreto-Lei no341/93, de 30 de Setembro (isto é, a Tabela Nacional de Incapacidades por Acidentes de Trabalho e Doenças Profissionais). Isto porque era até então a única tabela de avaliação de incapacidades oficialmente existente no nosso país. E esta situação resultava também claramente do disposto no Decreto-Lei n ${ }^{\circ}$ 202/96,

\footnotetext{
Instituto Nacional de Medicina Legal, I.P.

2 Faculdade de Medicina da Universidade de Coimbra

3 CENCIFOR - Centro de Ciências Forenses, Portugal
} 
de 23 de Outubro ${ }^{4}$, que estabelece o regime de avaliação de incapacidade das pessoas com deficiência, tal como definido no artigo $2 .^{\circ}$ da Lei n. ${ }^{\circ} 9 / 89$, de 2 de Maio, para efeitos de acesso às medidas e benefícios previstos na lei tendo em vista facilitar a sua plena participação na comunidade.

Mas o Decreto-Lei n ${ }^{\circ}$ 352/2007, de 23 de Outubro, veio posteriormente aprovar duas tabelas, uma destinada ao direito de trabalho, para a avaliação pericial de vítimas de acidentes de trabalho e doenças profissionais, e outra inteiramente direcionada para a reparação do dano em Direito Civil: a Tabela Nacional de Incapacidades por Acidentes de Trabalho e Doenças Profissionais (TNI) e a Tabela de Avaliação de Incapacidades Permanentes em Direito Civil.

Este novo quadro legal (as novas tabelas) não refere jamais quaisquer regras de aplicabilidade na avaliação específica de incapacidades em pessoas com deficiência, para efeitos de acesso às medidas e benefícios previstos na lei. Por outras palavras, não se definiu qualquer tabela específica para tais situações, ou seja, se seria de passar a utilizar neste âmbito a Tabela de Avaliação de Incapacidades Permanentes em Direito Civil, como pareceria lógico, face ao tipo de incapacidade em causa.

Nesta conformidade, teremos de concluir que permanece como instrumento pericial aplicável nas avaliações de incapacidade de pessoas com deficiência por força do Decreto-Lei n ${ }^{\circ}$ 202/96, de 23 de Outubro (“lei especial”), que não

4 Preâmbulo do Decreto - Lei $n^{\circ} 202 / 96$ de 23 de Outubro

O n. ${ }^{\circ} 1$ do artigo $2 .^{\circ}$ da Lei $n . .^{\circ}$ 9/89, de 2 de Maio - Lei de Bases da Prevenção e da Reabilitação e Integração das Pessoas com Deficiência - define pessoa com deficiência «aquela que, por motivo de perda ou anomalia, congénita ou adquirida, de estrutura ou função psicológica, intelectual, fisiológica ou anatómica suscetivel de provocar restrições da capacidade, pode estar considerada em situações de desvantagem para o exercício de atividades consideradas normais, tendo em conta a idade, o sexo e os fatores socioculturais dominantes».

Face à inexistência de normas específicas para a avaliação de incapacidade na perspetiva desta lei, tem sido prática corrente o recurso à Tabela Nacional de Incapacidades (TNI), aprovada pelo Decreto-Lei $n .^{\circ}$ 341/93, de 30 de Setembro, perspetivada para a avaliação do dano em vítimas de acidentes de trabalho e doenças profissionais, de forma a possibilitar alguma uniformização valorativa a nivel nacional.

Todavia, no âmbito da avaliação de incapacidade de pessoas com deficiência, mostra-se necessário proceder à atualização dos procedimentos adotados, nomeadamente de forma a melhor adequar a utilização da atual TNI ao disposto na Lei n. ${ }^{\circ}$ 9/89, de 2 de Maio. Considerando o conceito de pessoa com deficiência, enunciado no $n .^{\circ} 1$ do artigo $2 .^{\circ}$ da Lei $n .^{\circ}$ 9/89, de 2 de Maio - Lei de Bases da Prevenção e da Reabilitação e Integração das Pessoas com Deficiência; considerando que os benefícios fiscais e parafiscais previstos na lei para pessoas com deficiência são atribuídos com o intuito de realizar justiça social; considerando a necessidade não só de explicitar a competência para avaliação de incapacidade nas pessoas com deficiência como também, enquanto não for instituída uma tabela específica para este fim, criar normas de adaptação da citada TNI; considerando ainda a experiência adquirida pelas juntas médicas de avaliação de incapacidade de pessoas com deficiência. 
foi revogado pelo Decreto-Lei no 352/2007, de 23 de Outubro ("lei geral”) - a TNI (mas na sua nova versão do anexo I deste Decreto-Lei).

Note-se que a TNI (na sua versão atual) se aplica a todas as peritagens de danos corporais para avaliação do estado de saúde efetuadas após a sua entrada em vigor (verificada em Janeiro de 2008) ${ }^{5}$, independentemente da data em que tenha sido diagnosticada a deficiência ou estado patológico que fundamentou o pedido de avaliação.

No domínio da avaliação do estado de saúde, a intervenção dos serviços médico-legais tem surgido na sequência de solicitações das autoridades judiciárias e judiciais competentes, no âmbito de processos judiciais, inscrevendo-se plenamente nas suas competências enquanto órgão de apoio técnico aos tribunais. A intervenção do INML nas avaliações do estado de saúde, concretizada através dos seus peritos médicos, integra-se nas suas atribuições legais de prestação de serviços que envolvam conhecimentos médico-legais, conforme expressamente previsto na sua atual ${ }^{6}$ lei orgânica (alínea i, do n. 2 do artigo 3. ${ }^{\circ}$ do Decreto-Lei n. ${ }^{\circ}$ 131/2007, de 27 de Abril).

Mas tem igualmente surgido por iniciativa e a pedido de entidades públicas e privadas, bem como de particulares, para finalidades diversas (porventura não completamente esclarecidas nalguns casos): prova do seu estado de saúde, designadamente da incapacidade, para acionamento de contrato de seguro, para instrução de processo a apresentar na junta médica (situação a que se refere o artigo 2. ${ }^{\circ}$ Decreto-Lei n. ${ }^{\circ}$ 202/96, de 23 de Outubro, alterado e republicado pelo Decreto-Lei n. ${ }^{\circ}$ 174/97, 19 de Julho), ou para efeito de preparação do recurso hierárquico (de junta médica) para o diretor-geral da Saúde (cf. o artigo 5. ${ }^{\circ}$ do Decreto-Lei n. ${ }^{\circ}$ 202/96, de 23 de Outubro).

\section{MODELO DE AVALIAÇÃO PERICIAL}

A perícia médico-legal deve concretizar-se na forma de relatório pericial, decorrendo as realizadas no âmbito dos serviços do INML, em consonância com o modelo aprovado por este Instituto e com as metodologias específicas de cada domínio do direito, adequadas à avaliação pretendida. Refira-se que o INML não se encontra vinculado à utilização das instruções gerais e do modelo anexos ao Decreto-Lei n. ${ }^{\circ}$ 202/96, de 23 de Outubro, pois que se dirigem única e especificamente à avaliação em junta médica pelas autoridades aí designadas.

A elaboração do relatório pericial deve atender ao seguinte:

Alínea c) do $n^{\circ} 1$ do artigo $6^{\circ}$ do Decreto-Lei no 352/2007, de 23 de Outubro

6 À data de entrega deste trabalho para publicação. 
- Descrição pormenorizada e objetiva da perda ou da anomalia, congénita ou adquirida, de estrutura ou função psicológica, intelectual, fisiológica ou anatómica suscetível de provocar restrições da capacidade do examinando;

- Interpretação dos elementos observados e elaboração de conclusões devidamente fundamentadas.

Nesta conformidade, a elaboração do relatório pericial neste âmbito, deve envolver os seguintes capítulos: a) Identificação; b) Informação (compreendendo os subcapítulos: "História do Evento" e "Dados Documentais"); c) Antecedentes; d) Estado Atual (compreendendo os subcapítulos: "Queixas", "Exame Objetivo" e "Exames Complementares"); e) Discussão (sendo que, tal deverá ser substituída por conclusões preliminares, caso não seja possível concluir o relatório de forma definitiva); f) Conclusões.

Caso as conclusões finais possam ser formuladas, deverá elaborar-se previamente o capítulo da discussão, que deve contemplar obrigatoriamente, sob a forma de texto, a resposta ao objeto da perícia solicitada, quer seja a fixação de uma incapacidade, da compatibilidade ou não para o exercício da atividade profissional ou da necessidade de dependências (ajudas de terceira pessoa, técnicas, medicamentosas ou adaptação do domicílio, veículo ou local de trabalho).

Finalmente cabe referir que a avaliação pericial do estado de saúde deve ser efetuada cautelosamente, porque cada caso é um caso, todos distintos e particulares no seu conteúdo, devendo o perito médico ter um conhecimento geral do regime jurídico relativo a cada avaliação solicitada.

\section{ANÁLISE DE ALGUNS CASOS}

A intervenção pericial médico-legal nas situações de avaliação do estado de saúde ficará seguramente melhor exemplificada se nos debruçarmos sobre casos concretos. Utilizaremos alguns dos avaliados no Serviço de Clínica Forense da Delegação do Centro do INML:

Caso 1: Exame pericial efetuado em 2010, tendo sido solicitada a atribuição de incapacidade. Tratava-se de examinada de 50 anos de idade, reformada por invalidez (funcionária de estação de abastecimento de combustível) e portadora de uma doença natural, crónica - polimiosite, que se traduzia por um quadro de défice muscular generalizado, disfagia e sintomas depressivos crónicos. Com base na TNI (Anexo I do Decreto-Lei $n^{\circ} 352 / 2007$ de 23 de Outubro) e na capacidade restante 
da examinada que não lhe permitia a realização de qualquer tipo de atividade profissional, foi proposta a atribuição de uma incapacidade permanente absoluta para toda e qualquer profissão (IPA), o que, de acordo com a alínea 3 das Instruções Gerais da Tabela, deve ser expresso pela unidade. Foi ainda considerado que o quadro sequelar apresentado condicionava a autonomia da examinada para a realização dos atos correntes da vida diária, familiar e social, com necessidade de ajuda de terceira pessoa para a maioria dessas atividades, tratamentos medicamentosos, fisiátricos e controlos médicos e analíticos regulares.

Caso 2: Exame pericial solicitado pela entidade patronal em 2006, para avaliação da compatibilidade entre a atividade profissional que o examinado executava e a patologia de que era portador, atendendo a que não havia sido atribuída invalidez pelos peritos do Instituto de Segurança Social. Tratava-se de examinado de 59 anos de idade, operário fabril, com queixas álgicas cervicais e lombares, poliradiculopatia cervical moderada, canal raquidiano estenótico por alterações uncovertebrais, conflito de espaço com as raízes C5-C6, procidência herniária a nível de C3-C4 e radiculopatia a nível de L5-S1 à esquerda, tendo sido submetido a tratamento cirúrgico a hérnia discal lombar. Além de uma claudicação da marcha e limitações dolorosas dos segmentos cervical e lombar da coluna, apresentava um quadro angodepressivo, sem melhoria substancial com a terapêutica instituída. Ao ser solicitada uma avaliação da sua aptidão para a atividade profissional que desempenhava, tornou-se imprescindível que ao processo pericial fosse anexada uma acurada análise do seu posto de trabalho bem como a caracterização detalhada da sua atividade laboral. Do relatório da Medicina do Trabalho, constatou-se que a sua atividade exigia a posição ortostática frequente para a realização das tarefas, tração e elevação de cargas superiores a $25 \mathrm{~kg}$ e esforços que não eram tolerados pelo examinado. Nesta conformidade, foi proposta a atribuição de uma incapacidade total e permanente (incompatibilidade) para o exercício da sua profissão. Acresce-se que as perícias relativas à incapacidade para o trabalho por motivos de doença natural são geralmente da responsabilidade do Instituto de Segurança Social, contudo, cada vez mais, o Instituto Nacional de Medicina Legal (INML, I.P.) tem sido confrontado com situações desta natureza. Nestes casos, é fundamental proceder-se à avaliação de determinados fatores, entre os quais, as exigências das condições de saúde do examinado em relação à sua profissão. Deste modo, é de grande relevância a avaliação das condições de trabalho e das tarefas exercidas pelo examinado. 
Caso 3: Exame pericial solicitado pelo examinado em 2010, para a atribuição de uma incapacidade, com a finalidade de aquisição de dístico para estacionamento de veículos de pessoas com deficiência. Tratava-se de examinado com 85 anos de idade, reformado, submetido a cistoprostatectomia radical, por neoplasia invasiva da bexiga, hérnia do hiato, urgência miccional com crises de incontinência urinária, patologia degenerativa da coluna cervico-dorso-lombar, gonartrose bilateral moderada e ciatalgia esquerda. Ao exame objetivo, apresentava fralda descartável, distensão abdominal, limitação dolorosa dos segmentos cervical e lombar da coluna, sinal de Lasègue positivo à esquerda e uma limitação do movimento de flexão do joelho esquerdo, compatível com o processo artrósico referido. O regime jurídico relativo à aquisição do dístico de estacionamento de veículos para pessoas com deficiência (Decreto-Lei $n^{\circ} 307 / 2003$ de 10/12) ${ }^{7}$, só considera pessoa com deficiência motora, se portadora de incapacidade motora permanente, ao nível dos membros e de grau igual ou superior a $60 \%$. No caso em concreto, foi proposta a atribuição de uma incapacidade motora a nível dos membros, inferior a 60\% (com recurso à Tabela Nacional de Incapacidades para Acidentes de Trabalho e Doenças Profissionais).

Caso 4: Exame pericial solicitado por autoridade judicial em 2010, para avaliação da incapacidade permanente parcial, "incapacidade genérica e funcional" do examinado e sua eventual aptidão para a atividade profissional, com o objetivo de usufruir de eventuais benefícios fiscais e/ ou sociais. Referia-se a examinado com 35 anos de idade, reformado por invalidez (mecânico e motorista de reboque), a quem foi diagnosticada uma leucemia linfoblástica aguda cinco anos antes e tendo efetuado

7 Decreto - Lei 307/2003 de 10 de Dezembro (Dístico de estacionamento para deficientes)

Artigo 2. ${ }^{\circ}$ Pessoa com deficiência profunda - Para efeitos do presente diploma, considera-se pessoa com deficiência motora toda aquela que, por motivo de lesão, deformidade ou enfermidade, congénita ou adquirida, seja portadora de deficiência motora, ao nível dos membros inferiores ou superiores, de carácter permanente, de grau igual ou superior a 60\%, avaliada pela Tabela Nacional de Incapacidades, aprovada pelo Decreto-Lei $n .^{o} 341 / 93$, de 30 de Setembro, desde que tal deficiência lhe dificulte, comprovadamente: a) A locomoção na via pública sem auxílio de outrem ou sem recurso a meios de compensação, nomeadamente próteses e ortóteses, cadeiras de rodas, muletas e bengalas, no caso de deficiência motora ao nível dos membros inferiores;

b) O acesso ou utilização dos transportes públicos coletivos convencionais, no caso de deficiência motora ao nível dos membros superiores.

Artigo $3 .^{\circ}$ Pessoa com multideficiência profunda - Para efeitos do presente diploma, considera-se pessoa com multideficiência profunda qualquer pessoa com deficiência motora que, para além de se encontrar nas condições referidas no artigo anterior, enferme cumulativamente de deficiência sensorial, intelectual ou visual de carácter permanente de que resulte um grau de incapacidade igual ou superior a $90 \%$. 
tratamento quimioterápico com término em Janeiro de 2009, após protocolo de manutenção. Foi ainda submetido a uma artroplastia total da anca direita, por necrose asséptica da cabeça femoral. À data do exame pericial, apresentava-se sem evidência de doença hematológica e o exame objetivo era compatível com as limitações inerentes a uma prótese total da anca (limitação dos movimentos de rotação externa e flexão da anca). Foram colocados inúmeros quesitos pelo advogado, muitos relacionados com a sua aptidão para a atividade profissional. Não se reportando o caso em concreto a um pedido de esclarecimentos de uma avaliação pericial prévia, mas sendo uma primeira avaliação, não se procedeu a uma resposta direta aos quesitos, mas à elaboração de um relatório, contemplando-se todos os aspetos relevantes da avaliação pericial, bem como, indiretamente, a resposta aos quesitos colocados. Atendendo a que o examinado era portador de prótese total da anca, foi proposta a atribuição de uma incapacidade permanente parcial (IPP) de $30 \%$, com recurso à TNI e uma incapacidade permanente absoluta para o trabalho habitual, devido à perda de função inerente ao desempenho do posto de trabalho que ocupava. Quanto à "incapacidade genérica e funcional" solicitada, foi o advogado informado que tal só poderia ser valorado em sede de avaliação do dano corporal pós-traumático em Direito Civil, o que não se aplicava no caso em apreço. Foi ainda contemplado no relatório médico-legal que apesar de à data do exame pericial o examinado se apresentar sem evidência de doença hematológica, só poderia ser considerado curado cinco anos após o término dos tratamentos efetuados, o que ainda não havia ocorrido. Face ao exposto, é fundamental relembrar que sempre que o grau de incapacidade arbitrado seja suscetível de variação futura, tal deverá ser indicado.

Caso 5: Exame pericial solicitado por autoridade judicial em 2010, para avaliação do atual estado de saúde do examinado, detido em estabelecimento prisional e da compatibilidade dos tratamentos às patologias de que é portador com a sua atual situação prisional. Tratava-se de examinado, com 55 anos de idade, a quem foram solicitados exames complementares das especialidades de Endocrinologia (Diabetologia), Cardiologia e Psiquiatria, com o objetivo de confirmar ou não as patologias de que referiu ser portador (diabetes mellitus; cardiopatia isquémica e hipertensão arterial) e se estas se encontravam clinicamente compensadas. Constatou-se ser portador de Diabetes Mellitus tipo II e que, apesar de medicado, apresentava uma descompensação clínica da patologia endócrina. Apresentava hipertensão arterial, medicado, mas com picos hipertensivos decorrentes do seu estado psicológico atual. 
Apresentava ainda episódio depressivo major e doença aterosclerótica estabelecida, com risco elevado de doença coronária (hipertrigliceridémia, HTA, DM, sedentarismo e stress psicológico).

O INML tem sido confrontado com solicitações de exames periciais relativos às condições de saúde de examinados, no âmbito de processos penais e a propósito da estimativa da capacidade de um indivíduo de se submeter a uma situação prisional. O perito médico deverá, pois, definir as reais condições de saúde dos arguidos (presos preventivamente ou condenados) e a sua compatibilidade com o ambiente prisional, considerando as condições das instalações da unidade prisional e a capacidade dos respetivos serviços de saúde, assim possibilitando determinar se existem razões para adiar ou substituir a prisão (seja enquanto medida de coação ou enquanto pena efetiva). Não existem instruções específicas relativas à descrição do estado de saúde, ou seja, do que seria uma contraindicação, temporária ou permanente, para a participação em processos judiciais ou ficar em condições de encarceramento. Os prováveis pressupostos analisados referem-se, essencialmente, à idade, ao sexo e ao tipo de doenças somáticas de que seja portador.

Caso 6: Exame pericial requerido por autoridade judicial em 2010, para avaliação da atual situação clínica da examinada (com 15 anos de idade) e a compatibilidade com as suas condições habitacionais, onde residiu de 1997 a 2002. Tratava-se de uma examinada, que desde os 2 anos de idade iniciou episódios repetidos de infeções respiratórias altas (rinites, adenoidites e otites), broncorreactividade com tosse noturna e discrepância dento-maxilar. Na sua infância, coabitava numa residência com humidade extrema, cheiro a colas e vernizes, infiltrações de águas nas paredes e bolores em camada espessa nas paredes e armários. Foram colocados inúmeros quesitos, entre os quais, se o quadro clínico atual da examinada era afetado pelas condições habitacionais que teve de suportar na infância e qual o grau de Quantum Doloris para todo o período em que permaneceu em ambiente de extrema humidade. Tal como referido anteriormente, foi elaborado um relatório onde se admitiu que os quadros de infeção respiratória eram compatíveis com os altos índices de humidade que teve de suportar e que a sua permanência em tais condições, agravavam tal quadro clínico. Atualmente, não tomava qualquer medicação tendo referido apenas tosse seca, irritativa, sobretudo noturna e com temperaturas frias e húmidas. Atendendo à multiplicidade etiológica da tosse seca, bem como ao facto de esta ocorrer em temperaturas frias (quando as infeções respiratórias 
são mais frequentes), não foi possível admitir o nexo de causalidade entre os factos ocorridos de 1997 a 2002 e a situação clínica atual da menor, nem tão pouco, entre as condições habitacionais onde residia e os seus problemas dentários. Quanto à valoração quantitativa do Quantum Doloris solicitada, não foi efetuada, tendo sido referido que tal parâmetro era valorado no âmbito da avaliação do dano corporal pós-traumático em sede de Direito Civil, o que não se sucedia no caso em apreço.

Nas avaliações efetuadas neste âmbito, podemos ainda deparar-nos com situações de ações de despejo ou averiguações da capacidade de procriação.

\section{CONCLUSÕES}

Da análise dos casos expostos pode concluir-se o seguinte:

1 - A avaliação do estado de saúde pode ser feita a pedido de entidades diversas, públicas e privadas, bem como de particulares.

2 - A avaliação do estado de saúde pode ser realizada por motivos variados, designadamente compatibilidade entre o exercício da atividade profissional e a deficiência de que é portador, compatibilidade entre os tratamentos às patologias e a situação prisional, determinação de incapacidade no âmbito de contrato de seguro, obtenção de dístico de estacionamento, obtenção de benefícios fiscais, entre outros.

3 - A avaliação do estado de saúde pode servir para instrução de processo a apresentar a junta médica ou para preparação de recurso hierárquico para o diretor-geral da Saúde, de acordo com o Decreto-Lei n²02/96 de 23 de Outubro.

4 - Deve ser utilizada a versão mais atual da Tabela Nacional de Incapacidades por Acidentes de Trabalho e Doenças Profissionais em todas as peritagens de avaliação do estado de saúde, mesmo que tal estado seja anterior à entrada oficial em vigor da tabela.

5 - No âmbito da avaliação do estado de saúde deve ser elaborado um relatório completo, que inclui os diversos capítulos aprovados pelo INML no que se refere à avaliação do dano corporal em geral, exceto 
nas Juntas Médicas previstas no Decreto-Lei n²02/96 de 23 de Outubro, nas quais deve ser utilizado o modelo específico aí previsto.

\section{REFERÊNCIAS BIBLIOGRÁFICAS}

Decreto-Lei n. ${ }^{\circ}$ 202/96, de 23 de Outubro

Decreto-Lei n. ${ }^{\circ}$ 307/2003, de 10 de Dezembro

Decreto-Lei n. ${ }^{\circ} 352 / 2007$, de 23 de Outubro

Resumo: A avaliação de pessoas com deficiência suscetível de provocar restrições da sua capacidade e limitações no exercício de atividades consideradas normais constitui um tipo de perícia cada vez mais solicitada aos serviços médico-legais. No âmbito deste tipo de exames constata-se uma grande variabilidade de entidades requisitantes e de objetos da perícia, sendo pretendida, designadamente, a atribuição de incapacidades para efeitos de acesso a benefícios fiscais/sociais previstos na lei ou a atribuição ou não da compatibilidade entre o exercício da atividade profissional e o estado de saúde do examinado, bem como a necessidade de ajuda complementar para a realização de determinados atos. Sempre que solicitada uma avaliação de incapacidade e tal como definido no Decreto-Lei n n $^{202 / 96}$ de 23 de Outubro, aplicar-se-á a TNI (na versão do anexo I do Decreto-Lei n³52/2007 de 23 de Outubro) em todas as peritagens efetuadas neste âmbito e realizadas após a entrada em vigor daquela Tabela.

A perícia médico-legal deverá concretizar-se na forma de relatório médico-legal, devendo o capítulo da discussão contemplar uma resposta aos quesitos formulados (objeto da perícia).

Palavras-chave: Avaliação do estado de saúde; deficiência; TNI.

Summary: The forensic assessment of people with disabilities able to cause capacity restrictions and limitations in the exercise of activities, are expert examinations increasingly required to medico-legal services. Under this type of evaluation we see a great variety of entities requesting and objects of expertise, addressing the attribution of incapacity for access to fiscal/social benefits prescribed by law, or the assignment of compatibility between the exercise of professional activity and health status of the person subject to examination, as well as necessity for additional aid to carry out certain acts. Whenever requested an incapacity evaluation, and as defined in Decree-Law $n^{\circ} 202 / 96$ of 23 October, we will apply the National Table of Incapacities - TNI (in the version of Annex I of Decree-Law $n^{0} 352 / 2007$ of 23 October) at all examinations performed in this field and held after the entry of that table.

The medico-legal expertise should be implemented in the form of a medical-legal report, and the discussion's chapter must include answers to the questions formulated (subject expertise).

Key-words: Forensic assessment of health; disability; TNI. 
Résumé: L'évaluation des personnes portant des handicaps susceptibles de provoquer des contraintes de capacité et des limitations dans l'exercice d'activités considérées normales, sont des compétences de plus en plus requises dans les services médico-légaux. Dans le cadre de ce type d'examens, on observe une grande variabilité d'entités et d'objets de la demande d'expertise, s'adressant aux allocations d'invalidité pour obtenir des avantages fiscaux / sociaux prescrits par la loi, ou l'attribution ou non de la compatibilité de l'exercice de l'activité professionnelle et l'état de santé de la personne examinée, ainsi que la nécessité d'une aide supplémentaire pour accomplir certains actes. Chaque fois qu'est demandée une évaluation d'invalidité, et tel que défini dans le Décret-loi nº 202/96-loi du 23 0ctobre, on appliquera la Table National d'Invalidités - TNI (la version de l'annexe I du Décret-loi n 352/2007 de 23 0ctobre) dans toutes les expertises effectués dans ce cadre et réalisées après l'entrée en vigueur de ce tableau.

L'expertise médico-légale devra se concrétiser sous la forme d'un rapport médico-légal, et le chapitre de la discussion doit inclure des réponses aux questions formulées (objet de l'expertise).

Mots-clés: Évaluation de l'état de santé, handicap, TNI.

\section{PEDIDO DE SEPARATAS:}

\section{CARINA OLIVEIRA}

carina.oliveira@dcinml.mj.pt 